\title{
THE “METEOROLOGICAL RADIATION MODEL”
}

\section{Harry D. Kambezidis, Anastassios D. Adamopoulos and Nick K. Sakellariou}

Atmospheric Research Team, Institute of Meteorology and Physics of the Atmospheric Environment, National Observatory of Athens, P.O. Box 20048, GR-11810 Athens, Greece, Tel.: +30-1-3490119, Fax: +30-1-3490140, E-mail harry@env.meteo.noa.gr

\author{
Harry G. Pavlopoulos
}

Dept. of Statistics, Athens University of Economics and Business, GR-10434 Athens, Greece, Tel.: +30-1-8203527, Fax: +30-18230488, E-mail hgp@hermes.aueb.gr

\section{Ricardo Aguiar}

INETI/ITE/DER, Estrada do Pa ço do Lumiar, PT-1699 Lisbon, Portugal, Tel.: +351-1-7165141, Fax: +351-1-7163797, E-mail ricardo.aguiar@ite.ineti.pt

\section{Julia Bilbao and Argimiro de Miguel}

Dept. of Applied Physics I, Faculty of Sciences, University of Valladolid, Prado de la Magdalena, S/N, ES -47005 Valladolid, Spain, Tel.: +39-6-9100312, Fax: +39-6-9160614, E-mail 100640.1506@ compuserve.com

\section{Emanuele Negro}

Energy Consulting, Les Perrièress, Chem. De Bib émus, F-13100 Aixen Provence, France, Tel.: +33-44-2965021, Fax: +33-442230528, E-mail negro.ec@wanadoo.fr

\begin{abstract}
The estimation of hourly and daily solar radiation values on inclined surfaces starts with the determination of the corresponding hourly values on the horizontal plane. To serve the latter purpose the Meteorological Radiation Model was developed. The goal of the model is to estimate solar radiation at places where there are not available measurements. This work presents a theoretical description of the code and gives comparison between meas urements and estimated values for Athens, Lisbon and a Japanese location.
\end{abstract}

\section{INTRODUCTION}

\subsection{General Information}

The estimation of hourly and daily solar radiation values on inclined surfaces starts with the determination of the corresponding hourly values on the horizontal plane. For this reason the Atmospheric Research Team (ART) at the National Observatory of Athens (NOA) developed a code named MRM (Meteorological Radiation Model) (Kambezidis et al. , 1993; Kambezidis et al., 1997). The goal of the MRM development was to estimate (broadband) solar radiation on the horizontal plane at places where such measurements are not available, but meteorological data (air temperature, relative humidity, barometric pressure and sunshine duration) can be found and be used as input values to the model. The use of MRM as a tool in deriving simulated broadband solar radiation values is particularly useful for the generation of Solar Atlases in areas with a moderately dense meteorological network.

The original form of MRM (MRM v1) worked efficientl under clear-sky conditions, but presented some drawbacks under partly cloudy conditions; it became even less efficient in cases of overcast-sky conditions. Most of these deficiencies were resolved via implementation of a second version (MRM v2), derived by T. Muneer's research team (Muneer et al., 1998) after a cooperation with ART. Through the CEC JOULE III project on Climatic Synthetic Time Series for the Mediterranean Belt (CliMed), a further development of MRM was achieved (MRM v3) with four sub-versions (v3.1-v3.4). In this edition, attention was paid to the influence of ground albedo on previous versions (v1 and v2).

The present work gives a brief description of the MRM evolution and gives its theoretical basis. Since MRM has been designed to be a tool for engineers, architects and all those dealing with solar radiation estimation, a comparison between measurements and estimated values through MRM v3 for Athens and Lisbon is presented in this paper. Since these estimations are based on daily sunshine duration values used by MRM v3, a comparison for a Japanese location is also shown; in this latter example, the estimation of MRM was based on hourly sunshine duration values and a dramatic improvement is shown. In the latter $\mathrm{c}$ ase, MRM can also be used as research tool.

There have been developed several broadband solar radiation models and appeared in the international literature (e.g. Dave, 
1979; Louche et al., 1988; Perez et al ., 1990; Reindl et al., 1990). Some of these have followed a statistical development; others are based on a detailed input of parameters. This is the difference between those and MRM. The latter is an atmospheric-physics-based model and has been designed to require a minimum number of (meteorological) data which are available in every national meteorological network.

\subsection{Theoretical development of MRM}

This Section gives a brief description of the 3 versions of MRM developed so far.

\subsubsection{MRM version 1}

\subsubsection{Beam irradiance for cloudless skies}

According to Iqbal (1983), the direct component normal to a horizontal plane (also referred to as beam horizontal irradiance) under clear sky and natural atmosphere is given $b$ the formula:

$\mathrm{G}_{\mathrm{b}}=\mathrm{G}_{\mathrm{ex}} \tau_{\alpha} \tau_{\mathrm{r}} \tau_{\mathrm{o}} \tau_{\mathrm{w}} \tau_{\mathrm{mix}}$

where $\mathrm{G}_{\mathrm{ex}}$ is the extraterrestrial solar irradiance on a plane normal to the solar rays on any Julian day, which is given $b$ Muneer (1997), $\mathrm{G}_{0}=1367 \mathrm{Wm}^{-2}$ (the solar constant), and $\tau_{\alpha}$ $\tau_{\mathrm{r}}, \tau_{\mathrm{o}}, \tau_{\mathrm{w}}, \tau_{\mathrm{mix}}$ are the optical transmittances due to Mie and Rayleigh scattering, and ozone, water vapor and mixed gases (i.e. $\mathrm{CO}_{2}, \mathrm{O}_{2}$, etc) absorption, respectively. The transmittances can be estimated by analytical expressions (Iqbal, 1983 for $\tau_{\alpha}$; Davies et al., 1975 for $\tau_{\mathrm{r}}$; Lacis and Hansen, 1974 for $\tau_{\mathrm{o}}$ and $\tau_{\mathrm{w}}$; Bird and Hulstrom, 1981 for $\left.\tau_{\text {mix }}\right)$. The computation of these transmittances requires the knowledge of air temperature $\left({ }^{\circ} \mathrm{C}\right)$, relative humidity $(\%)$ and barometric pressure $(\mathrm{hPa})$.

\subsubsection{Sky diffuse irradiance for cloudless skies}

The Rayleigh-scattered, $\mathrm{G}_{\mathrm{dr}}$, and aerosol-scattered, $\mathrm{G}_{\mathrm{d} \alpha}$, diffuse horizontal components are estimated through expressions based on the results of studies made by Dave (1979) and Bird and Hulstrom (1979), respectively. Their sum gives the diffuse component, $\mathrm{G}_{\mathrm{d}}$.

\subsubsection{Global irradiance for cloudless skies}

The global irradiance, G, on a horizontal surface, under clear skies, is therefore given by the sum of the beam and the diffuse irradiance, so that

$\mathrm{G}=\mathrm{G}_{\mathrm{b}}+\mathrm{G}_{\mathrm{d}}$

However, the effect of multiple ground -atmosphere reflections can be accounted for, scaling Eq. (2) by the adequate factor $\left(1-\rho_{\mathrm{g}} \rho_{\alpha}^{\prime}\right)^{-1}$ :

$$
\mathrm{G}=\left(G_{b}+G_{d}\right) \frac{1}{1-\rho_{g} \rho_{a}^{\prime}}
$$

where $\rho_{\mathrm{g}}$ is the ground albedo (having usually a reference value of 0.2 or being computed by e.g. Kambezidis et al., 1997), and $\rho_{\alpha}^{\prime}$ is the albedo of the cloudless sky. The latter can be computed according to Muneer (1997).

\subsubsection{Cloudy skies}

In the case of partly cloudy or overcast skies, the beam, $\mathrm{G}^{\prime} \mathrm{b}$, and diffuse, $\mathrm{G}_{\mathrm{d}}^{\prime}$, components are modified to:

$\mathrm{G}_{\mathrm{b}}^{\prime}=\frac{S D}{S D_{0}} \mathrm{G}_{\mathrm{b}}$

$\mathrm{G}_{\mathrm{d}}^{\prime}=\frac{S D}{S D_{0}} \mathrm{G}_{\mathrm{d}}+\mathrm{K}^{*}\left(1-\frac{S D}{S D_{0}}\right) \mathrm{G}$

where $\mathrm{SD}$ is the measured and $\mathrm{SD} 0$ the theoretical dail sunshine duration on a particular day, in hours; $\mathrm{K}^{*}=0.33$ for $\varphi=40^{\circ} \mathrm{N}$ (after Berland and Danilchenco, 1961). $\mathrm{SD}=0$ in the case of overcast sky, $\mathrm{SD}<\mathrm{SD}_{0}$ in the case of partly cloudy sky, and $\mathrm{SD}=\mathrm{SD}_{0}$ in the case of clear sky. Other values of $\mathrm{K}^{*}$ are 0.32 for $\varphi=30^{0} \mathrm{~N}, 0.32$ for $\varphi=35^{0} \mathrm{~N}, 0.34$ for $\varphi=45^{0} \mathrm{~N}$. In all cases of cloudy skies:

$\mathrm{G}^{\prime}=\mathrm{G}_{\mathrm{b}}^{\prime}+\mathrm{G}_{\mathrm{d}}^{\prime}$

MRM has proved to be a very suitable tool for engineering calculations not only because of its simplicit but also because of its accuracy. In most cases the estimation error in the dail global irradiation is less than 10\% (Kambezidis et al., 1997).

\subsubsection{MRM version 2}

Version 2 treats the cases of clear and overcast skies exactl as v1 does, but deals more efficiently with the cases of partl cloudy sky conditions. Muneer et al. (1996) have recognized a log-log linear relationship between the hourly diffuse-to-beam ratio $\left(\mathrm{DBR}=\mathrm{G}_{\mathrm{d}}^{\prime} / \mathrm{G}_{\mathrm{b}}^{\prime}\right)$ and the beam clearness index $\left(\mathrm{K}_{\mathrm{b}}=\right.$ $\left.\mathrm{G}_{\mathrm{b}}^{\prime} / \mathrm{G}_{\mathrm{ex}}\right)$ in the form:

$\mathrm{DBR}=\mathrm{A} \mathrm{K}_{\mathrm{b}}{ }^{\mathrm{C}}$

where $\mathrm{A}$ and $\mathrm{C}$ are parameters to be estimated via a linear least-squares method applied to observed data of DBR and $\mathrm{K}_{\mathrm{b}}$. The practical merit of Eq. (7) is that it can be used to substitute Eq. (5) to estimate values of diffuse irradiance without requiring sunshine data, based on values of beam and extraterrestrial irradiance

$\mathrm{G}_{\mathrm{d}}{ }^{\prime}=\mathrm{G}_{\mathrm{b}}{ }^{\prime} \mathrm{A} \mathrm{K}_{\mathrm{b}}{ }^{\mathrm{C}}$.

The global horizontal irradiance in MRM v2 is, therefore, estimated as

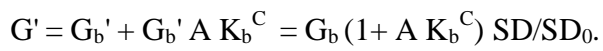

\subsubsection{MRM version 3}

MRM v3 discerns between four similar but different sub versions denoted by v3.1, v3.2, v3.3, and v3.4, defined explicitly hereafter. These developments were accomplished within the framework of the JOULE III project CliMed (Aguiar, 1997). 
MRM v3.1 estimates G' via Eq. (6) under overcast skies, via Eq. (9) under partly cloudy skies (as in v2), and via Eq. (2) under clear skies (as in v1). MRM v3.2 estimates $\mathrm{G}^{\prime}$ exactly as $\mathrm{v} 3.1$, and then scales it by the factor $\left(1-\rho_{\mathrm{g}} \rho_{\alpha}^{\prime}\right)^{-1}$ in order to account also for multiple ground and atmospheric reflections. Diffuse values are calculated as in v3.1. MRM v3.3 estimates global horizontal irradiance for overcast and partially cloud skies again just as in v3.1, but uses Eq. (9) instead of Eq. (2) under clear skies (i.e. with $\mathrm{SD}=\mathrm{SD}_{0}$ ). $\mathrm{MRM}$ v3.4 estimates global horizontal irradiance as in v3.3, and then scales it by the factor $\left(1-\rho_{g} \rho_{\alpha}^{\prime}\right)^{-1}$. The diffuse values are calculated exactly as in v3.1.

\section{DATA COLLECTION}

During the CliMed project a large volume of data from sites in France, Greece, Italy, Portugal and Spain was collected. Imposing criteria referring to climatic zones, proximity of stations and completeness of the data series did a first filtering of the data. All data that pa ssed the above criteria underwent a further quality control procedure regarding the span of air temperature, relative humidity, irradiance (global and diffuse) and sunshine duration. The data sets from Athens $\left(\varphi=37.97^{\circ} \mathrm{N}\right.$, $\lambda=23.72^{\circ} \mathrm{E}, \mathrm{h}=107 \mathrm{~m}$ a.m.s.1. $)$ and Lisbon $\left(\varphi=38.7^{\circ} \mathrm{N}, \lambda=9.1^{\circ}\right.$ $\mathrm{W}, \mathrm{h}=70 \mathrm{~m}$ a.m.s.1.) were the only ones from the data base to include hourly values of both global and diffuse horizontal irradiance along with all other meteorological parameters needed for the MRM algorithm. Even so, the values of barometric pressure were missing from both data sets, and therefore this parameter has been set at $1013.25 \mathrm{hPa}$ throughout this work. The period covered by the Athens $\mathrm{d}$ ata ranges from May 5, 1989 through September 28, 1993, corresponding to 14528 hourly data points. The period covered by the Lisbon data ranges from January 1, 1985 through December 31, 1989, corresponding to 22838 of hourly data points. Because of the qua lity control criteria, the sizes of the data sets at the two locations were reduced to 11848 and 20495, respectively.

\section{RESULTS}

This Section gives a set of Figures for the two locations. Each set comprises four diagrams corresponding to the four sub models of MRM v3. The $\mathrm{x}$-axis in all cases is the measured irradiation $\left(\mathrm{Jcm}^{-2}\right)$ and the $\mathrm{y}$-axis the simulated values $\left(\mathrm{Jcm}^{-2}\right)$ through the MRM sub-models. It is worth noting that for the calculation of the simulated diffuse values in the subsequent Equations the dai ly sunshine duration was used. Figure 1 shows the above diagrams for Athens and Figure 2 for Lisbon.

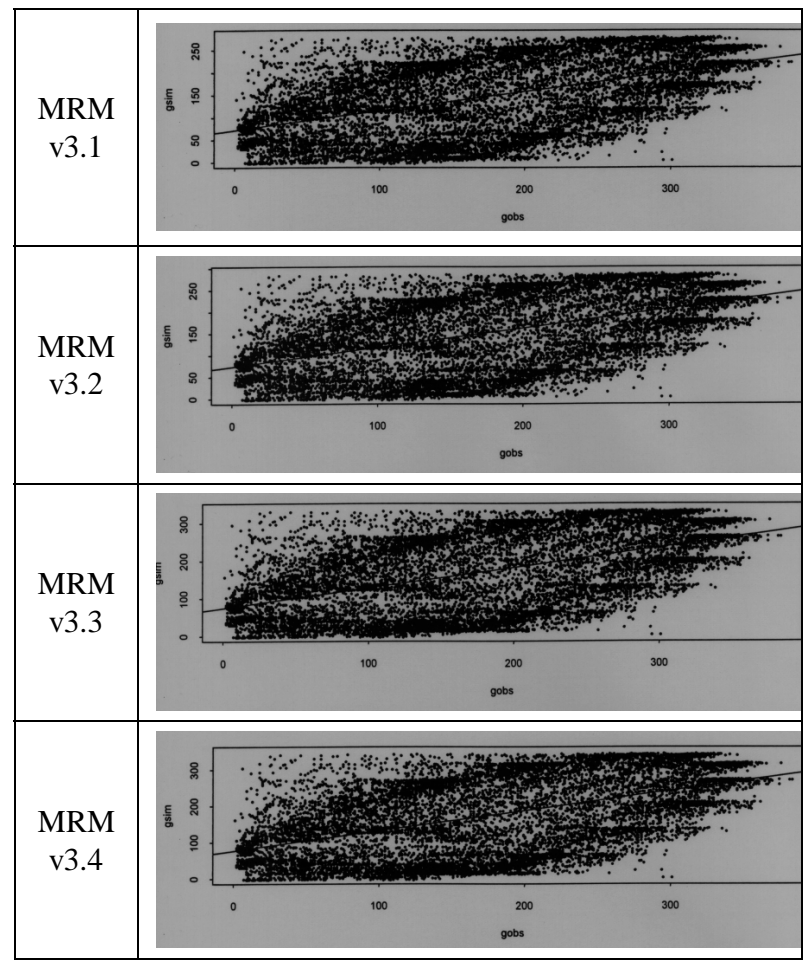

Fig. 1. Simulated vs. measured global horizontal irradiation values $\left(\mathrm{Jcm}^{-2}\right)$ for Athens in the period 5/5/1989 - 28/9/1993. The simulated values were computed using the four submodels of MRM v3.

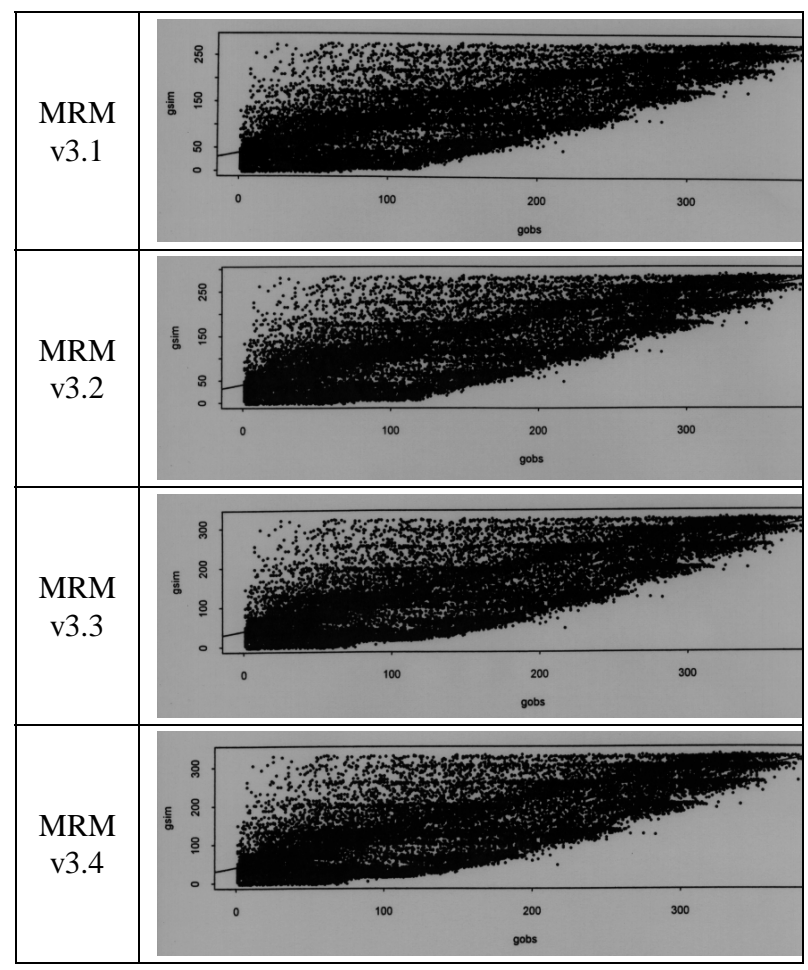

Fig. 2. Simulated vs. measured global horizontal irradiation values $\left(\mathrm{Jcm}^{-2}\right)$ for Lisbon in the period 1/1/1985 - 31/12/1989. 
The simulated values were computed using the four submodels of MRM v3.

The reason for having a greater offset in the regression lines in the case of Athens comes from the fact of worse qualit measured diffuse values than in the case of Lisbon. This is reflected in the MBE (Mean Bias Error, $\mathrm{Jcm}^{-2}$ ) and RMSE (Root Mean Square Error, $\mathrm{Jcm}^{-2}$ ) for both locations. If $\mathrm{N}$ is the number of measurements, MBE and RMSE are expressed as follows

$\mathrm{MBE}=\Sigma($ estimated value-observed value $) / \mathrm{N}$

RMSE $=\left[\Sigma(\text { estimated value }- \text { observed value })^{2} / \mathrm{N}\right]^{1 / 2}$.

\begin{tabular}{|c|c|c|}
\hline \multicolumn{3}{|c|}{ Table 1. MBE $\left(\mathrm{Jcm}^{-2}\right)$ and RMSE $\left(\mathrm{Jcm}^{-2}\right)$ for the cases of } \\
& Figs 1 and 2. & Lisbon \\
\hline Sub-model & Athens & MBE=17 \\
\multirow{2}{*}{ MRM v3.1 } & MBE=29.4 & RMSE $=50.3$ \\
\hline \multirow{2}{*}{ MRM v3.2 } & MBE=25 $=72.6$ & MBE=13.1 \\
& RMSE=74.8 & RMSE=51.9 \\
\hline \multirow{2}{*}{ MRM v3.3 } & MBE=7.1 & MBE=-0.5 \\
& RMSE=89.5 & RMSE=59.2 \\
\hline \multirow{2}{*}{ MRM v3.4 } & MBE=2 & MBE $=-4.8$ \\
& RMSE=92.3 & RMSE=61 \\
\hline
\end{tabular}

Table 1 gives the above statistics for Athens and Lisbon.

One main observation from Table 1 is that MBE and RMSE behave reciprocally. Since MBE reflects the data dispersion around the best -fit line and has to be kept as minimum as possible, this is the controlling factor to choose which sub model works best. In the case of Athens sub -model 4 is the best and for Lisbon sub-model 3. Another statistical outcome can be the correlation coefficient, $r$, for the best -fit curves; which is around $49 \%$ in the case of Athens and $77 \%$ in the case of Lisbon.

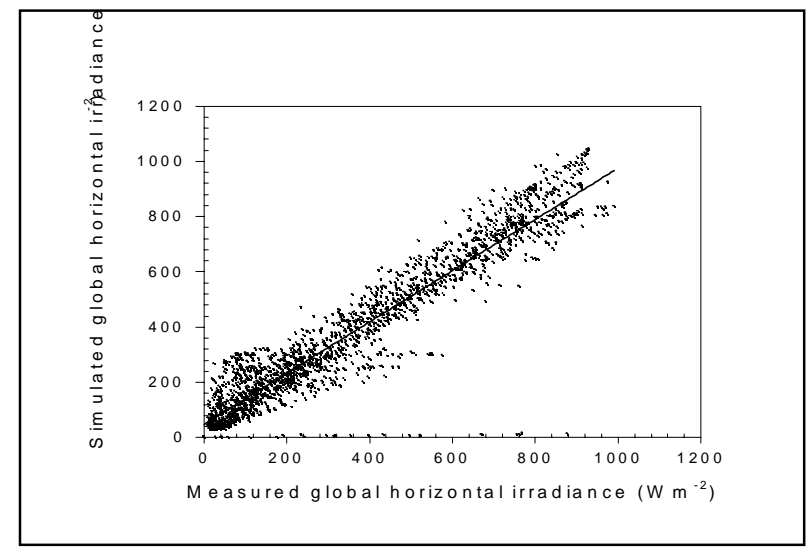

Fig. 3. Simulated vs. measured global horizontal irradiance values $\left(\mathrm{Wm}^{-2}\right)$ at Fukuoka for 1994. The simulated values were computed using the MRM v3.3.
To demonstrate the effectiveness in using hourly sunshine values instead of the daily ones, Fig. 3 below shows simulated irradiance values vs. measured ones at Fukuoka, Japan. The correlation coefficient of the best-fit curve is now $94.7 \%$. This implies a 20\% improvement in MRM efficiency.

\section{CONCLUSIONS}

This paper showed the versatility and applicability of MRM for engineering and architecture purposes. In the case of its use as a research tool for more accurate results, detailed sunshine information must be provided as for Japan.

\section{ACKNOWLEDGEMENT}

Sincere thanks are expressed to Dr. T. Muneer, Dept. of Mechanical, Software and Manufacturing Engineering, Napier University, Edinburgh, UK for disposing Japanese da ta of Fig. 3. Thanks are also addressed to CEC DG12 for funding CliMed project.

\section{REFERENCES}

Aguiar R. (1997) Climatic synthetic series for the Mediterranean belt. Final Technical Report, CEC Contract No. JOR-CT96-0042.

Berland G. and Danilchenco V.Y.(1961 ) The continental distribution of Solar Radiation, Gidrometeorzdat, St. Peterburg.

Bird R.E. and Hulstrom R.L. (1979) Application of Monte Carlo technique to insolation characterization and prediction. US SERI Tech. Report RR-36-306.

Bird R.E. and Hulstrom R.L. (1981) A simplified clear-sky model for the direct and diffuse insolation on horizontal surfaces US SERI Tech. Report TR-642-761, 38.

Dave J.V. (1979) Extensive data sets of the diffuse radiation in realistic atmospheric models with aerosols and comm on absorbing gases. Solar Energy 21, 361-369.

Davies J.A., Schertzer W. and Nunez M. (1975) Estimating global solar radiation. Boundary-Layer Meteorol. 9, 33-52.

Iqbal M. (1983) An introduction to solar radiation, Academic Press, NewYork.

Kambezidis H.D., Psiloglou B.E., Tsangrassoulis A.E., Logothetis M.A., Sakellariou N.K. and Balaras C.A. (1993) meteorology to give solar radiation on titled plane from meteorological data. In Proceedings of ISES World Congress, Farkas J. (ed), pp. 99-104, Budapest, Hungary.

Kambezidis H.D., Psiloglou B.E. and Synodinou B.M. (1997) Comparison between measurements and models of daily total irradiation on tilted surfaces in Athens, Greece. Renew. Energy 10, 505-518. 
Lacis A.A. and Hansen J.E. (1974) A parameterization for the absorption of solar radiation in the earth's atmosphere. $J$. Atmos. Sci. 31, 118-132.

Louche G., Simonot M., Iqbal M. and Merneir M. (1988) Experimental verification of some clear-sky insolation models. Solar Energy 41, 273-279.

Muneer T., Gul M., Kambezidis H.D. and Alwinkle S. (1996) An all-sky solar meteorological radiation model for the United Kingdom. In Proceedings of CIBSE/ASHRAE Joint National Conf., CIBSE/ASHRAE (Eds), pp. 271-280, Harrogate, UK.

Muneer T. (1997) Solar radiation and daylight mo dels for the energy efficient design of buildings, $1^{\text {st }}$ edn, pp. 65-70, Architectural Press.

Muneer T., Gul M. and Kambezidis H.D. (1998) Evaluation of all-sky meteorological model against long -term measured hourly data. Energy Conv.\& Manag. 39, 303-317.

Perez R., Ineichen P. and Seals R. (1990) Modelling daylight availability and irradiance components from direct and global irradiance. Solar Energy 44, 271-289.

Reindl D.T., Beckman W.A. and Duffie J.A. (1990) Evaluation of hourly tilted surface radiation models. Solar Energy 45, 9-17. 